\title{
Rapid Processing Techniques Applied to Sintered Nickel Battery Technologies for Utility Scale Applications
}

\author{
J. D. Marinaccio, I. Mabbett, C. Glover, D. Worsley
}

\begin{abstract}
Through use of novel modern/rapid processing techniques such as screen printing and Near-Infrared (NIR) radiative curing, process time for the sintering of sintered nickel plaques, applicable to alkaline nickel battery chemistries, has been drastically reduced from in excess of 200 minutes with conventional convection methods to below 2 minutes using NIR curing methods. Steps have also been taken to remove the need for forming gas as a reducing agent by implementing carbon as an in-situ reducing agent, within the ink formulation.
\end{abstract}

Keywords-Batteries, energy, iron, nickel, storage.

\section{INTRODUCTION}

$\mathrm{E}$ LECTRICAL energy storage research at SPECIFIC is focused on the optimization of materials and processes for large-scale printable batteries utilizing rapid sintering techniques. SPECIFIC's Pilot-line facilitates the up-scaling of laboratory-optimized products. The Nickel-Iron (Ni-Fe) battery chemistry has been identified as a suitable solution to provide highly distributed micro-storage for highly distributed micro generation, such as solar photovoltaics and wind, at utility scale. Properties, such as tolerance of overcharge/discharge, sizable cycle life (up to 4,000 deep charge/discharge cycles), and extended useful life (20 years), as well as raw material abundance and low costing of raw materials [1]-[3] all give credence to this proposal.

It is reported that sintered plaque electrodes improve the high-rate capabilities of Ni-Fe technology [4], however manufacture via conventional methods, such as convection oven sintering is typically very costly and labor intensive [1]. These issues make the production of sintered plate/plaque electrodes on a large scale for implementation in large scale energy storage operations less economically viable and less financially attractive. One way to make sintered plate technology a more viable option as a utility-scale energy storage solution is to improve process time by implementing modern/rapid processing techniques. The aim of the current study is to investigate modern/rapid processing techniques such as screen printing and NIR (Near Infra-Red) curing and their applicability to production of sintered nickel plaques.

J. D. Marinaccio is with Swansea University, Swansea, SA2 8PP UK (email: 800634@swansea.ac.uk).

I. Mabbett, C. F. Glover, and D. A. Worsley are with Swansea University/SPECIFIC, Swansea, SA12 7AX, UK (e-mail: I.mabbett.@ swansea.ac.uk, C.F.Glover@swansea.ac.uk,D.A.Worsley@swansea.ac.uk).

This research is joint sponsored by TATA steel colors/TATA steel and WEFO/EPSRC/ESF
The use of these techniques should result in reductions in process time (and as a result reduce process cost by enabling potential for continuous/roll to roll manufacture).

Near-infrared technology resembles the way microwave ovens utilize microwave radiation. Near-infrared radiation directly excites molecules within the target material by activating molecular vibrations of the molecules, as opposed to conventional oven heating mechanisms, such as convection and conduction, relying on heating the air in the vicinity of the target material and then the heat being conducted to the target materials. NIR heating techniques are highly dependent on the absorbance of materials and as such, the technique is well suited to darker colored coatings with good absorbance properties.

Screen printing is another high throughput manufacture technique, which can be scaled to rotary screen printing for roll to roll/continuous processing. Screen printing also allows for a consistent and even layer deposition, unlike some instances for loose powder or slurry depositions. The ability to create various plaque architectures may also prove useful to attain maximum performance from a given chemical composition.

This study discusses surface characteristics such as sinter structure and porosity as well as analysis of elemental composition, as a means of comparison between processing methods used.

\section{SCREEN PRINTING INK COMPOSITIONS}

\section{A. Base Ink}

Inks viable for screen printing have been formulated by Gwent Electronic Materials (GEM Ltd.) where a suitable binder/solvent system (vehicle) has been combined with filamentary nickel powder (T255 filamentary nickel, VALE) in suitable proportions to give suitable screen printable properties such as fineness of grind (FOG) and viscosity. An initial 'base' ink was formulated using filamentary nickel only.

Additional ink compositions have been formulated to incorporate additives which would have desirable effects, both upon the process itself and the final properties of the plaques.

\section{B. Ammonium Carbonate $\left(\left(\mathrm{NH}_{4}\right)_{2} \mathrm{CO}_{3}\right)$}

Ammonium carbonate $\left(\left(\mathrm{NH}_{4}\right)_{2} \mathrm{CO}_{3}\right)$ is used as a blowing agent to add porosity during sintered plaque formation [5]. When heated, ammonium carbonate will decompose via a 2 step reaction pathway; 


$$
\begin{aligned}
& \left(\mathrm{NH}_{4}\right)_{2} \mathrm{CO}_{3} \rightarrow \mathrm{NH}_{4} \mathrm{HCO}_{3}+\mathrm{NH}_{3} \\
& \mathrm{NH}_{4} \mathrm{HCO}_{3} \rightarrow \mathrm{NH}_{3}+\mathrm{H}_{2} \mathrm{O}+\mathrm{CO}_{2}
\end{aligned}
$$

This enhanced porosity is a desirable property and common practice within sintered plate technology to attain greater accessibility for active materials to adhere to the surfaces of the sintered plaque structure, giving improved loadings, utilization and energy densities.

\section{Bismuth Oxide $\left(\mathrm{Bi}_{2} \mathrm{O}_{3}\right)$}

Bismuth oxide was chosen for this study due to its ability to reduce sinter temperature. As an added effect of the larger $\mathrm{Bi}_{2} \mathrm{O}_{3}$ particle size, porosity may also be expected to improve [6]. This additive was decided upon retrospectively after the initial use of NIR sintering proved problematic at the energy settings required, due to limitations of some of the auxiliary equipment.

\section{D.Carbon}

Carbon was chosen as an additive in this study based on its reducing properties, especially those associated with oxides of nickel and other related metal oxides [7]. It has previously been used as an in situ reducing agent in powder metallurgy studies [8] for these properties. This would enable the reduction of any formed oxides, without the need for atmospheric control such as HNX gas during the sintering stage. Carbon reacts here via a carbothermic reduction mechanism; in which carbon monoxide and carbon dioxide are produced, resulting in the reduction of metal oxides to their pure metal state [8].

$$
2 \mathrm{MO}(\mathrm{s})+\mathrm{C}(\mathrm{s}) \rightarrow 2 \mathrm{M}(\mathrm{s})+\mathrm{CO}_{2}(\mathrm{~g})
$$

Two carbon sources have been utilized, a reducing carbon black (Super P, IMERYS), and a graphite powder (KS15 Graphite, Timcal). Different carbon sources have been chosen as various grades of carbon have been shown to exhibit their reducing properties at differing temperature ranges. Ink compositions are summarized in Table I.

TABLE I

INK COMPOSITIONS

\begin{tabular}{cc}
\hline \hline Ink & Additive \\
\hline Base & None \\
C2141215R3 & Carbon Black (Ensaco, Super P) \\
C2141215R4 & Graphite (Timcal, KS15) \\
C2141215R5 & Bismuth Oxide \\
C2141215R6 & Ammonium Carbonate \\
\hline \hline
\end{tabular}

\section{THERMOGRAVIMETRIC ANALYSIS}

Thermo-Gravimetric Analysis of Base ink composition has shown significant gravimetric losses in the ranges $140-160^{\circ} \mathrm{C}$ and $340-360^{\circ} \mathrm{C}$. These losses correspond to the solvent system and binder system losses, highlighting 2 steps which were to be accommodated for in heating profiles within the study.

\section{PRINTING/INK DEPOSITION}

Printing was carried out using an ATMA lab-scale screen printer (AT-45FA) where multilayer printing was carried out to obtain a variety of plaque thicknesses, as opposed to utilization of multiple screens for a desired thickness. Deposition was carried out on a nickel plated steel coupons $(0.2 \mathrm{~mm}$ gauge, $100 \mathrm{~mm} \times 100 \mathrm{~mm}$, TATA steel). Thicknesses obtained post drying (solvent removal at $150^{\circ} \mathrm{C}$, as indicated by Thermo-Gravimetric Analysis) are shown in Table II.

TABLE II

PLAQUE THICKNESS POST-SOLVENT REMOVAL

\begin{tabular}{cc}
\hline \hline Number of prints & Plaque thickness $(\mu \mathrm{m})$ \\
\hline 1 & 41 \\
2 & 112 \\
3 & 203 \\
4 & 276 \\
5 & 368 \\
\hline \hline
\end{tabular}

Plaques on smaller volume scale have also been manufactured via a basic doctor blade technique using a known tape thickness $(120 \mu \mathrm{m})$ to ensure consistent depositions. Nickel plated steel is again utilized as the substrate; however substrate dimensions are decreased to $500 \mathrm{~mm} \times 500 \mathrm{~mm}$. The same drying stage is employed here, however this step was commonly carried out in conjunction with the binder burn off and sinter operations.

\section{V.SINTERING}

\section{A. Convection Sintering}

All convection heating was carried out in a Lenton CSC $12 / 90 / 300 \mathrm{H}$ split tube furnace. Samples prepared via convection sintering were followed a variety of temperature profiles, shown in Fig. 1. The samples were all initially sintered in an inert nitrogen atmosphere. A suitable temperature profile for sinter operations was established through analysis carried out using Scanning Electron Microscopy (Hitachi TM3000 Tabletop Microscope) to assess the quality of the sinter achieved at each sinter profile and is discussed in section VI.

\section{B. Near Infrared Radiative Sintering (NIR)}

NIR sintering operations were carried out using an ADPHOS lab-scale unit ( $0.5 \mathrm{~m}$ heated length). Both line speed and power settings were varied to achieve suitable sinter characteristics/properties, comparable to those achieved by convection methods. The power settings and line speed parameters trialed are listed in Table III.

\section{RESULTS AND DISCUSSION}

The following results are obtained from samples which have been deposited via doctor blade technique (approx. $120 \mu \mathrm{m}$ ) from the base (additive free) ink. Scanning Electron Microscopy (SEM) techniques have been used for surface characterization to determine if acceptable surface characteristics (structure, porosity) were achieved upon sinter operation. Figs. 2 (a)-(d) show sintered structures achieved 
through convection sintering methods. Fig. 2 (d) shows a highly porous network with a large amount of necking observed, with no sign of partial melting phenomena being observed. This corresponds to profile E. Similar structures are observed in Figs. 2 (a) and (b), corresponding to sinter profiles
A and B. All 3 of these sinter profiles all have in common a 30 minute soak period at a temperature of $800^{\circ} \mathrm{C}$, suggesting that this is an appropriate soak time and temperature combination required to achieve desired sinter structures.

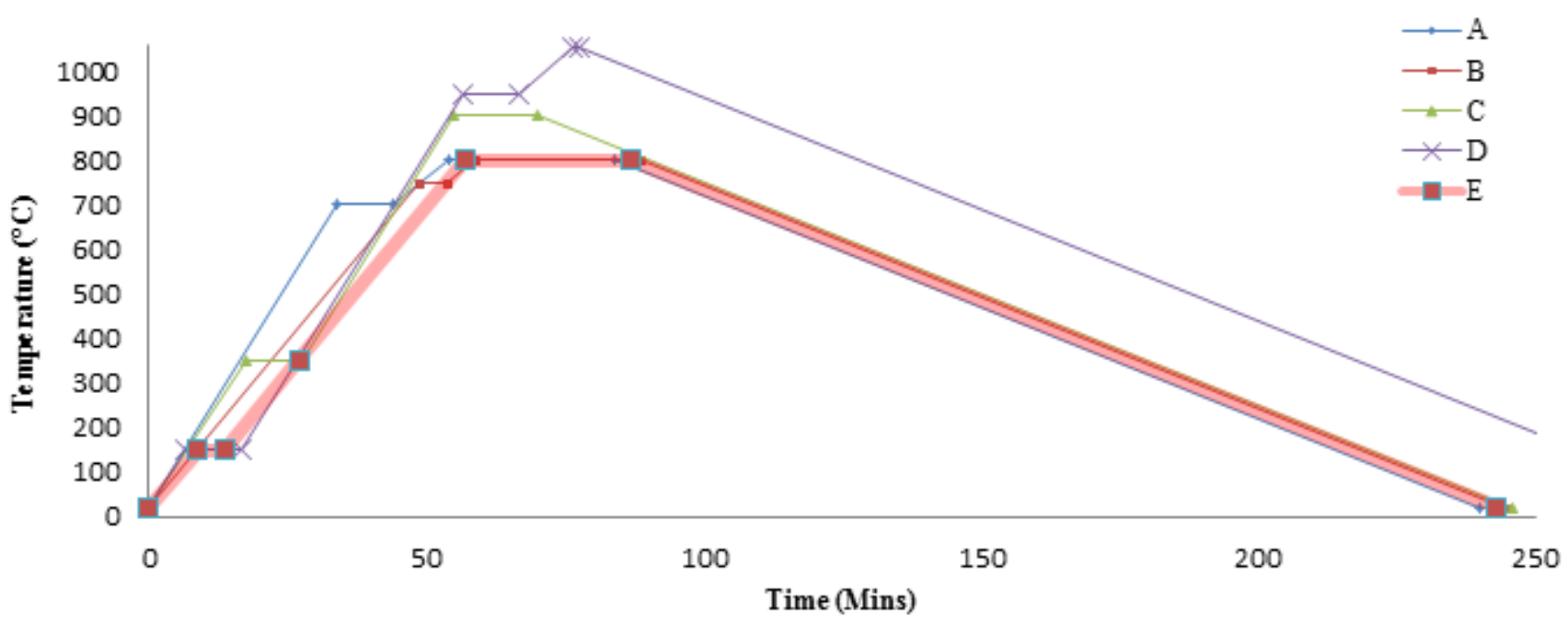

Fig. 1 Convection sintering temperature regimes

TABLE III

NIR PARAMETERS

\begin{tabular}{cccc}
\hline \hline Regime & Power Setting $(\%)$ & Line Speed $(\mathrm{m} / \mathrm{s})$ & Number of passes \\
\hline i & 60 & 4 & 1 \\
ii & 60 & 4 & 2 \\
iii & 60 & 4 & 3 \\
iv & 60 & 4 & 4 \\
v & 70 & 5 & 2 \\
vi & 70 & 4 & 2 \\
vii & 70 & 4 & 3 \\
viii & 70 & 4 & 4 \\
ix & 80 & 5 & 1 \\
x & 80 & 5 & 2 \\
xi & 80 & 5 & 3 \\
xii & 80 & 5 & 4 \\
\hline \hline
\end{tabular}

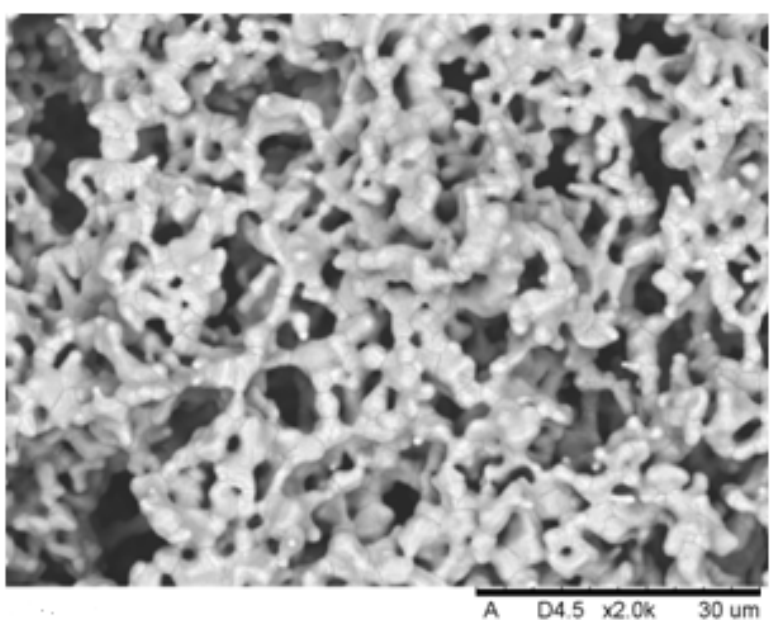

(a)

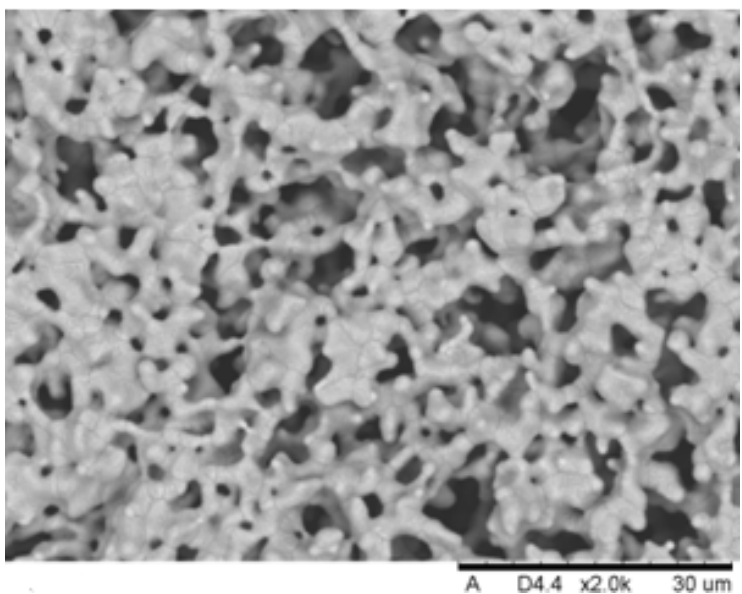

(b)

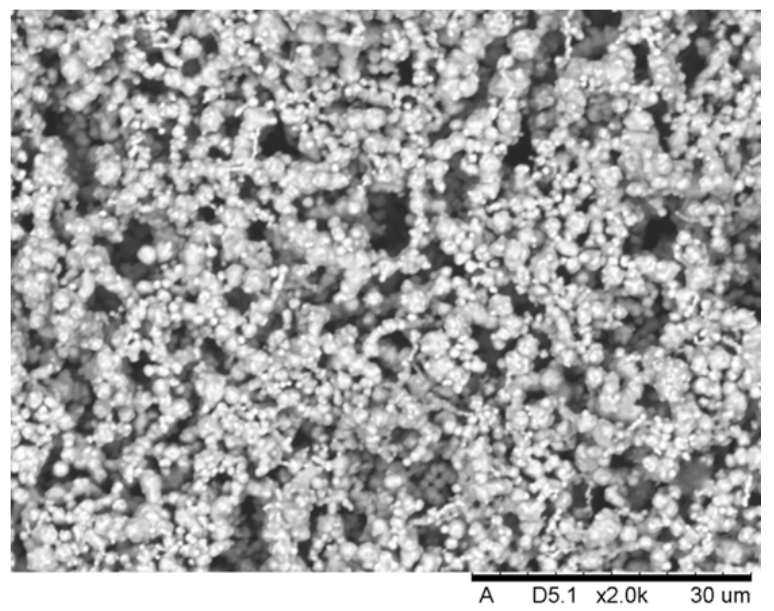

(c) 


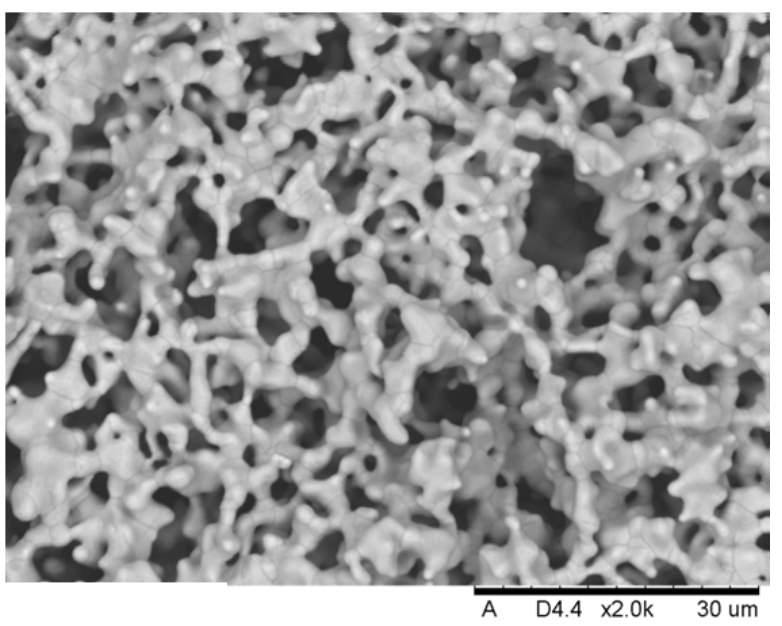

(d)

Fig. 2 (a) Sample convection sintered following regime A. (b) Sample convection sintered following regime B. (c) Sample convection sintered following regime C. (d) Sample convection sintered following regime $\mathrm{E}$

It is well known within the field of sintering, there is often a compromise between sinter surface area and adhesion. Adhesion testing was subsequently carried out to assess the suitability of the plaques produced. Tape testing in accordance with ASTM D3359 was carried out on samples which had gone through sintering at $800^{\circ} \mathrm{C}$ and it was found that samples which followed regime $\mathrm{E}$ passed the test with minimal cohesive and no adhesive failures of the "coating". From this it can be assumed that the binder burn off stage at $350^{\circ} \mathrm{C}$ is an important stage and without a "soak time" at this temperature to ensure slow and uniform removal of the binder system, the integrity of the plaque structure is compromised. From these results, profile $\mathrm{E}$ and its resulting samples were chosen as a base line comparison for all other sintering operations and ink compositions.

SEM images obtained from samples which have undergone NIR heating regimes are shown in Fig. 3. Various degrees of sintering and melting phenomena can be observed. Fig. 3 (c) arguably shows the highest degree of sintering, however it can also be said to be approaching a more melt-like structure where necking has been far surpassed and the formation of larger agglomerated structures becomes apparent. Upon close inspection however there do appear to be a multitude of very small pore structures dispersed randomly across the larger melt structures, a phenomenon which had not previously been observed during the study for convection sintered samples.

Energy Dispersive X-ray Spectroscopy (EDS) was carried out to analyze the elemental surface compositions of samples post sintering. Results showed the effects of included additives or control atmosphere changes during sintering, on the elemental composition of the final sinter structure. Samples sintered by the convection methods under flow of nitrogen showed very little surface oxide presence, with an average surface oxygen content of $4.76 \%$ (atom \% vs nickel). When nitrogen flow is ceased and the same procedure is followed for a new sample, a substantially increased oxygen presence is observed $(25.90 \%$ vs nickel). This observation falls in line with what would be expected for such a reaction in ambient atmosphere, given the accelerated oxidation rates of nickel at temperatures of above $400^{\circ} \mathrm{C}$.

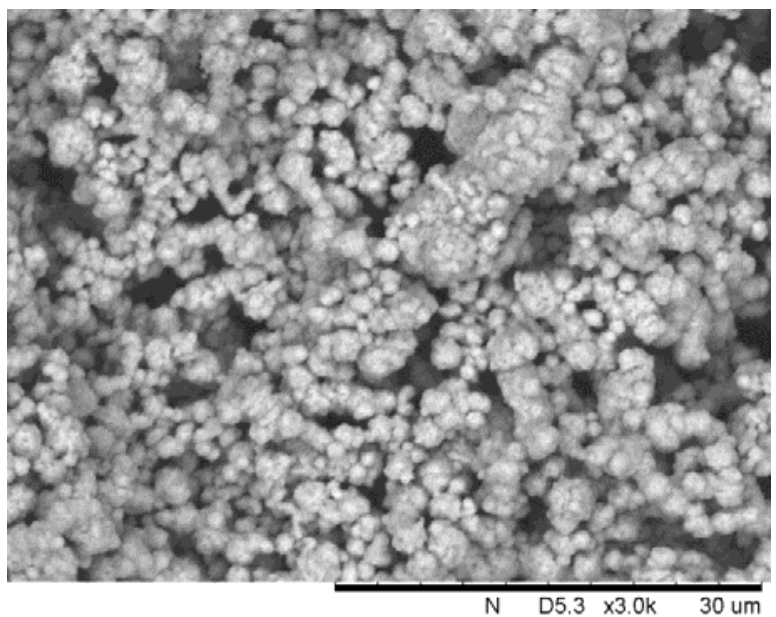

(a)

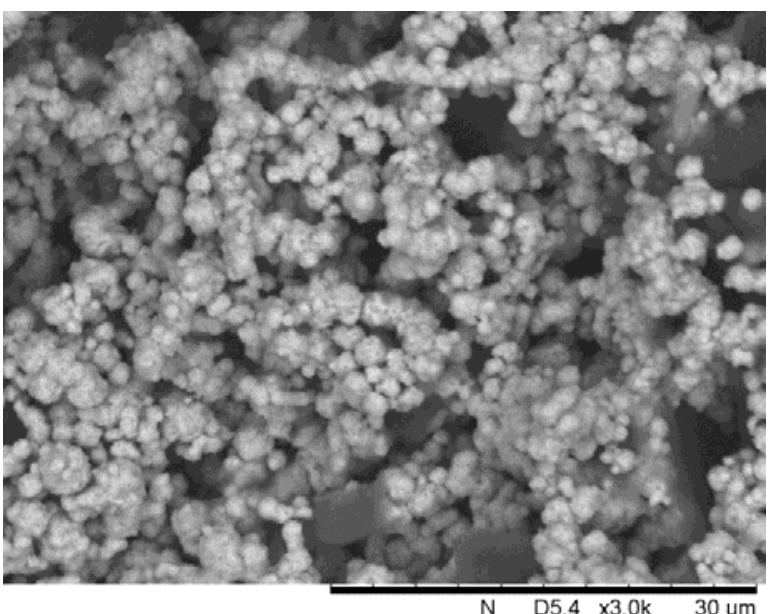

(b)

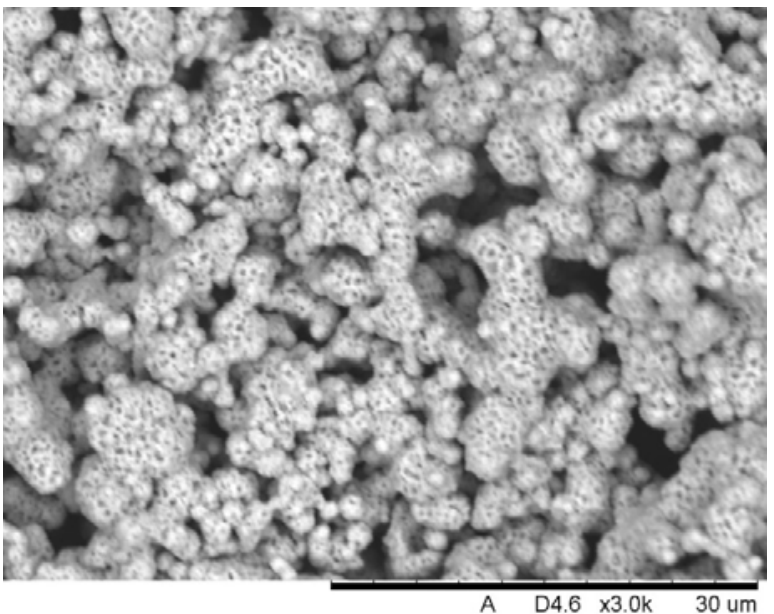

(c) 


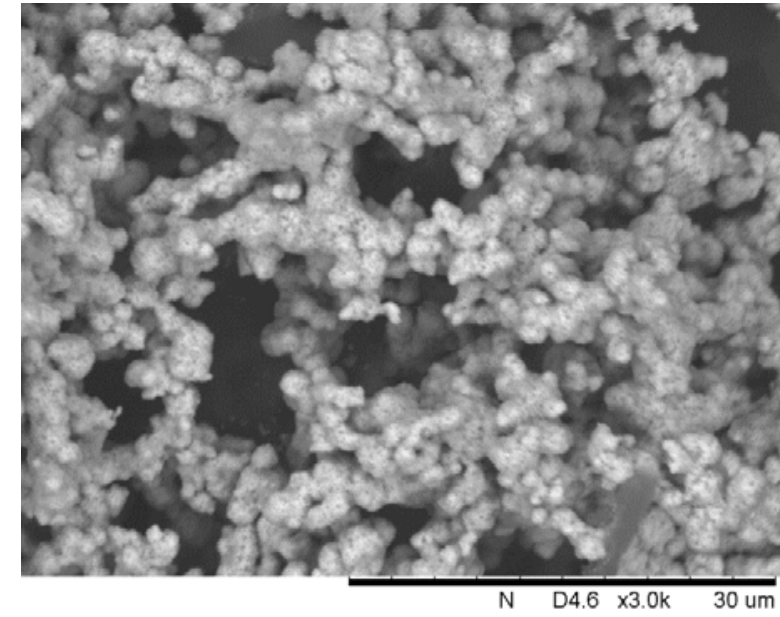

(d)

Fig. 3 (a) Sample NIR sintered following regime x. (b) Sample NIR sintered following regime vii. (c) Sample NIR sintered following regime xiii. (d) Sample NIR sintered following regime xi

Samples which were treated under the NIR method have been analyzed in the same manner. A similar picture is observed in this instance, with a large oxygen presence (32.61\% atom \% vs nickel). This suggests 2 things; 1$)$ the processing time is not sufficiently fast to avoid the rapid oxidation of nickel. 2) NIR sintering is creating more favorable conditions for the oxidation of nickel. Ink R4 (Timcal KS15 Graphite was subsequently sintered under NIR conditions to validate the theory of carbothermic reduction being able to reduce nickel oxides back to their pure metal forms. The resulting EDS spectra show that the small graphite inclusions of this ink does not sufficiently reduce the oxides formed during NIR heat treatment, with negligible reduction in oxygen content. In response to this, ink R4 was modified to increase its graphite content to $5 \mathrm{wt} \%$ and the modified ink was subsequently NIR heat treated as previously. Spectroscopic data post heat treatment show that oxygen presence is largely decreased when compared to the base ink sample which had undergone the same heat treatment. However the resulting oxygen content is still large when compared to samples which have been sintered under nitrogen (convection). A summary of these results are presented in Fig. 4

Further investigation is to be carried out to assess this effect of higher wt.\% additions of graphite into the ink, without compromising the plaque integrity. However if the previously mentioned reaction scheme for carbothermic reduction holds true, then it can be approximated that increased graphite additions would have a positive effect on overall plaque porosity post sinter, due to the loss of carbon during the aforementioned reactions. Further investigation on porosity is ongoing (Mercury Intrusion Porosimetry, MIP, and BET surface area analysis).

Inks R3-R6 were sintered following sinter profile $E$ however there was very little effect observed which could be linked to the additives included. This issue has been adjusted by new formulations, which have compositions shown in Table IV.

TABLE IV REVISED INK COMPOSITIONS

\begin{tabular}{ccc}
\hline \hline Ink & Additive & Additive (wt.\%) \\
\hline C2150518R3 & - & - \\
C2150518R4 & Carbon Black (Ensaco, Super P) & 20 \\
C2150518R5 & Graphite (Timcal, KS15) & 20 \\
C2150518R6 & Bismuth Oxide & 5 \\
C2150518R7 & Ammonium Carbonate & 20 \\
\hline \hline
\end{tabular}

The revised C2150518 series of inks have all been sintered in accordance with sinter profile $\mathrm{E}$ and have been analyzed via SEM and EDS as previous samples have. Scanning electron micrographs of the sintered plaques obtained from ink C2150518R7 are shown in Figs. 5 (a) and (b). Large pore structures induced by the decomposition of ammonium carbonate upon heating are visible at low magnification, with sizes varying between 1-100 micrometers. PSD (Pore Size Distribution) measurements will confirm this in future work.

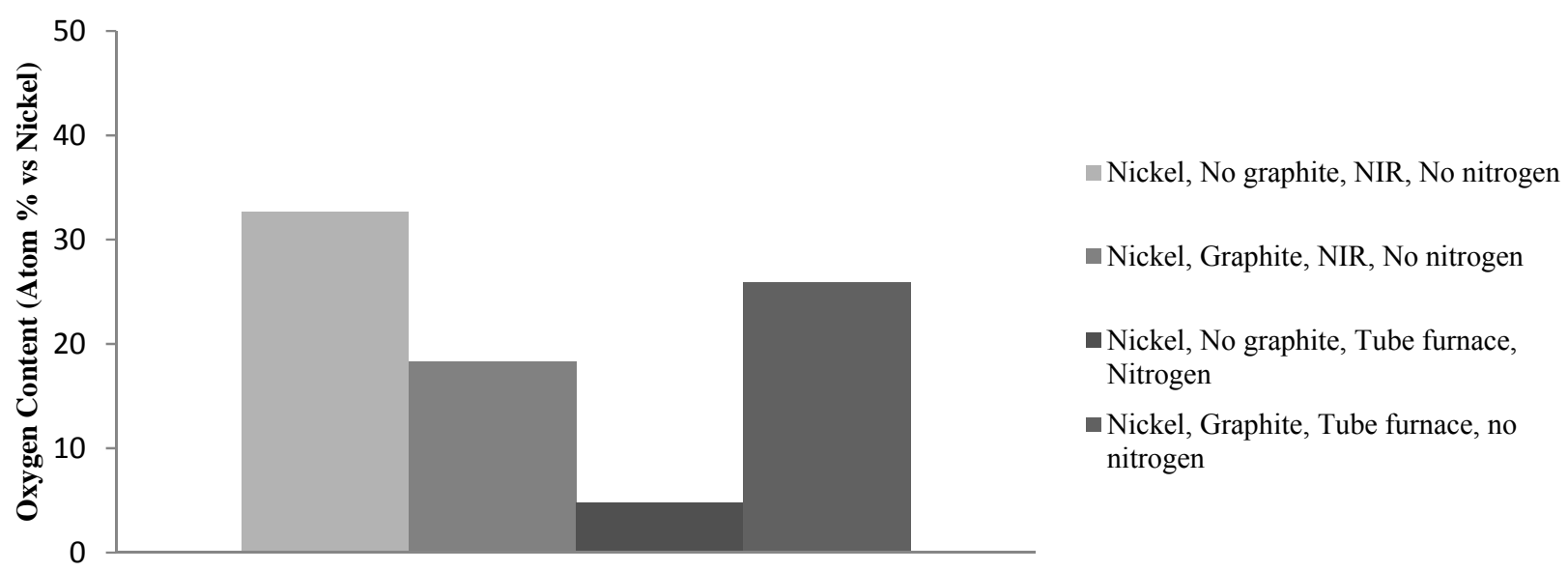

Fig. 4 Comparison of the effects of atmospheric control and graphite additions on oxide content post heat treatment 


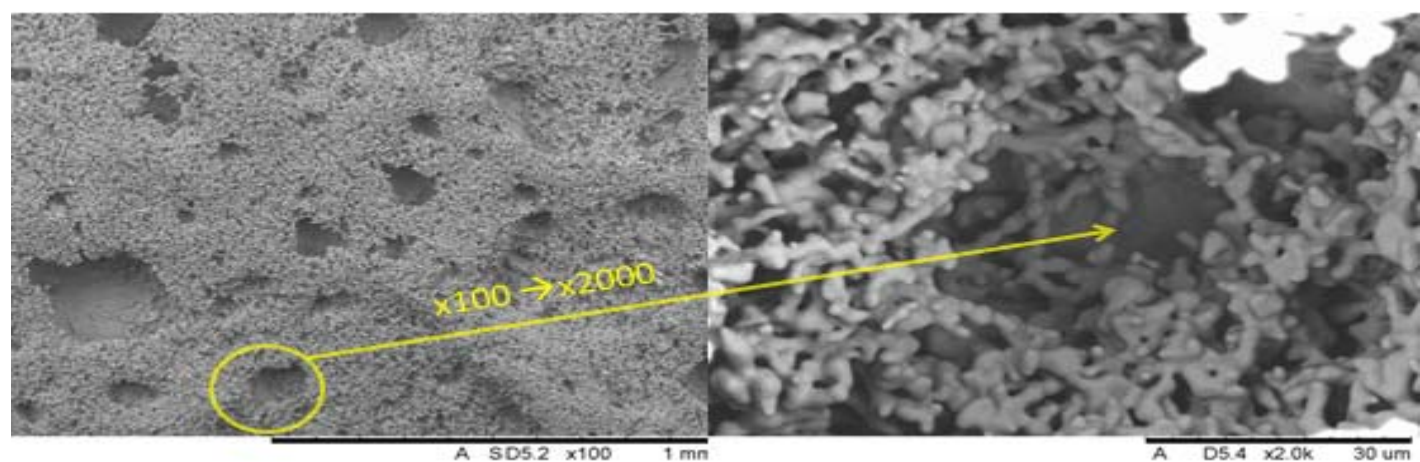

(a)

(b)

Fig. 5(a) Ink C2150518R7 (x100), (b) C2150518R7(x1000), image centered on large pore highlighted in (a)

Fig. 5 (b) also shows that particles within the depths of the inner structure of the plaque have successfully sintered.

Inks C2150518 R4, R5, R6 have been successfully sintered via convection methods with NIR heat treatments to follow.

\section{CONCLUSION}

In this study, the feasibility of using NIR radiative curing to sinter nickel plaques for battery applications has been explored. Progress has been made towards using this rapid processing technique to greatly decrease the time take to sinter nickel plaques, however a system with more accurate control is required to perfect the techniques use in this application. Facilities at SPECIFIC will be used to probe this further, with in depth trails using a Heraeus production scale unit.

Carbothermic reduction has proved to be an effective reducing agent for metal oxides in this rapid heating application. Future work with GEM Ltd and utilization of alternative grades of carbon will allow progress towards developing an ink which can offer greater reduction of metal oxides during plaque formation, while also maintaining the integrity and structure of the plaque.

\section{ACKNOWLEDGMENT}

The authors would like to thank Gwent Electronic Materials for their co-operation within the study and their expertise within the field of functional screen printing inks.

\section{REFERENCES}

[1] G. A. Bayles, "Chapter 18 Iron electrode batteries," in Linden's Handbook of batteries,, 4th ed. vol. 3, T. B. Reddy, Ed. New York: McGraw-Hill, 2011

[2] C. Chakkaravarty, P. Perisamy, S. Jegannathan, K. I. Vasu, J. Power Sources, 35, 1991, pp. 21-35.

[3] A. K. Shukla, S. Venugopalan, B. Hariprakash, J. Power Sources, 100, 2001, pp. 125-148.

[4] I. Mabbett, C. F. Glover, J. H. Malone, D. A. Worsley, ECS Transactions, 50, 2012, 45, pp. 25-35

[5] E. M. Rus, D. M. Constantin, L. Oniciu, L. Ghergari, Croatica, Chemica Acta, 72, 1999, pp. 25-41.

[6] V. Gil, J. Tartaj, C. Moure, P. Duran, J. of the European Ceramic Society 26, 2006, pp 3161-3171.

[7] B. V. L'vov, Thermochimica Acta, 360, 2, 2000, pp109-120

[8] A. Hadhud, "Design of reducing agent for sintering of high performance alloyed PM steels based on different carbon grades analysis", Diploma work No. 95/2012, Department of Materials and Manufacturing
Technology, Chalmers University of Technology, Gothenburg, Sweden, 2012. 